\section{sciendo}

DOI: $10.2478 /$ ncr-2018-0004

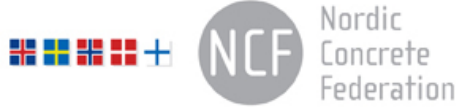

ISSN online 2545-2819

ISSN print $\quad 0800-6377$

Received: March 18, 2018

Revision received: May 15, 2018

Accepted: May 15, 2018

\title{
Full-scale Test of an Unreinforced Concrete Dome Plug for the Spent Nuclear Fuel Repository
}

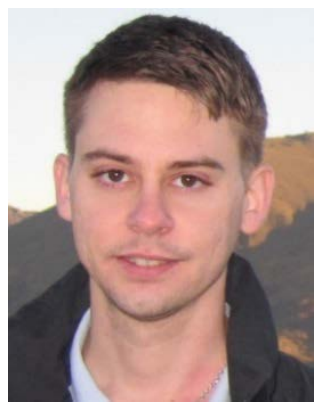

\author{
Richard Malm \\ Ph.D., Researcher \\ KTH Royal Institute of Technology \\ Division of Concrete Structures \\ SE-100 44 Stockholm \\ e-mail: richard.malm@byv.kth.se
}

\begin{abstract}
In the planned Swedish repository for spent nuclear fuel, plugs are designed to close the deposition tunnels. The outer part of these plugs consists of a concrete dome made with selfcompacting-concrete, designed to have low $\mathrm{pH}$ to reduce negative effects on the bentonite clay buffer. A full-scale test has been performed to evaluate the performance of the plug, to test the installation and to verify underlying design assumptions. In this paper, the behaviour of the concrete dome is evaluated based on measurements, from casting the concrete until it was subjected to $4 \mathrm{MPa}$ hydrostatic water pressure.
\end{abstract}

Key words: Nuclear, full-scale testing, concrete plug, shrinkage, cooling.

1.

\section{INTRODUCTION}

1.1

\section{The Swedish nuclear repository}

The Swedish Nuclear Fuel and Waste management Co (SKB) is responsible for developing the repository for spent nuclear fuel in Sweden. In the proposed concept for deposition, called KBS3 , the spent fuel will be installed in copper canisters with iron inserts. These will be placed in the crystalline rock at depth of about $500 \mathrm{~m}$ below ground in the repository in Forsmark. The canisters are placed in vertical holes in floor of the deposition tunnels and are enclosed with a pre-packed bentonite buffer. After all canisters are installed in a deposition tunnel, the tunnel will be filled with the pre-packed bentonite backfill. At the tunnel entrance, a plug will be placed as a temporary closure to allow for further deposition in the other deposition tunnels as 
seen in Figure 1. In total, about 100 deposition tunnels are planned to be built in the repository. The designed life-span of these plugs is only during the operation period of the repository, i.e. maximum of 100 years. When all deposition tunnels are backfilled and plugged, the adjacent main tunnel will also be filled with bentonite clay and in the end, all tunnels and shafts will be filled all the way up to the ground level, [1].

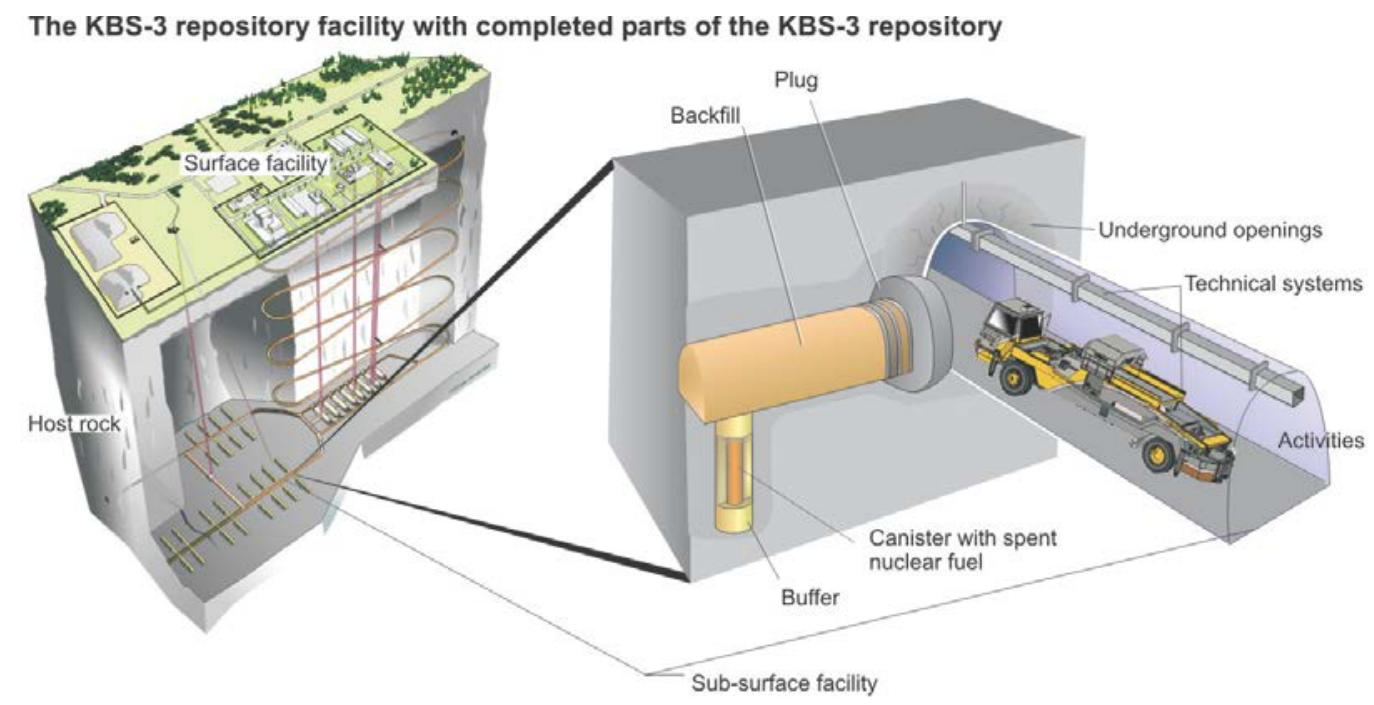

Figure 1 - Illustration of the KBS-3 repository, from [1].

The plug used to seal the deposition tunnels consists of several material layers, each with its specific purpose, see Figure 2. The main parts of the plug are; filter, bentonite seal and a concrete dome. The filter is needed to control ground water inflow during casting and hardening of the concrete dome through drainage pipes. The bentonite seal is intended to be the water-tight seal of the plug and should thereby prevent that leakages occur from the backfilled deposition tunnel to the adjacent main tunnel. The concrete dome constitutes the mechanical resistance intended to transfer the loads from swelling pressure of bentonite and the hydrostatic water pressure to the surrounding rock. The concrete dome has an octagonal shape with a concave downstream surface, and thereby carrying the horizontal pressure loads as a dome. The concrete dome is unreinforced and built with a specially developed concrete mix that is intended to have a lower $\mathrm{pH}$ than conventional concrete. The low $\mathrm{pH}$-concrete is described further in detail in the following section. Between these material layers, different delimiters are installed only to separate the materials. The delimiter closest to the concrete dome consists of concrete beams. 


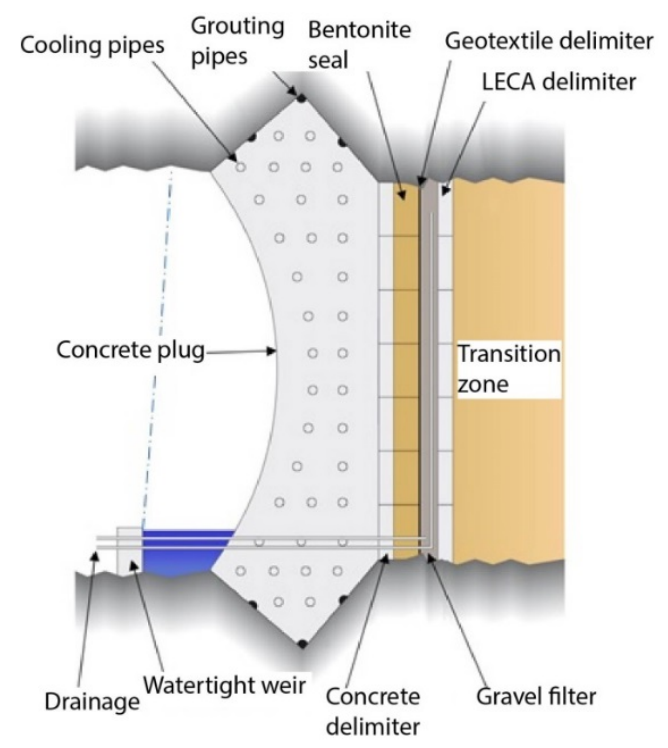

Figure 2 - Illustration of the reference design of plugs for the KBS-3 repository, from [1].

The concrete dome will theoretically be subjected to high pressure loads during the operation phase. The swelling pressure in the backfill is expected to be very high and therefore, the backfill closest to the plug (backfill transition zone) will be designed to reduce the swelling pressure acting on the concrete dome plug to $2 \mathrm{MPa}$. However, considering uncertainties in the expected swelling pressure, the concrete dome has been designed for a swelling pressure of $4 \mathrm{MPa}$. Thereby, the total pressure that the plug is designed for is $9 \mathrm{MPa}$, including the maximum hydrostatic water pressure of $5 \mathrm{MPa}$, i.e. $500 \mathrm{~m}$ of hydraulic head. The expected water pressure during operation of the repository is likely lower than this, considering that the remaining part of the tunnel system is open and the expected low natural inflow of water which means that it will take many years before the water pressure has been built up in the deposition tunnels. After the main tunnels (i.e. downstream of the plug) also are filled with bentonite, the concrete dome will be subjected to water pressure and swelling pressure from both sides and the plug does not fill any function in the repository after this.

In order to verify the concept for plugging the deposition tunnels, a full-scale test has been performed in Äspö Hard rock laboratory (HRL). The purpose of the full-scale test was firstly to test how the installation could be made and to ensure that it was possible to build the plug according to the design specifications. In addition, the purpose was also to evaluate that the design acted as expected during hardening and the serviceability state when it is subjected to hydrostatic pressure. Finally, the purpose was also to estimate the water tightness of the structure. However, in this paper the focus will be on the early age behaviour and especially to assess if the cooling of the dome worked as intended to break the bond between concrete and rock prior to grouting.

\section{2}

\section{Low pH-concrete}

The concrete mix used in the nuclear repository needs to have lower $\mathrm{pH}$ than conventional concrete. The reason for this is that high $\mathrm{pH}$ may influence the swelling properties of the bentonite clay. Therefore, a specific concrete mix had previously been developed and tested for this purpose that result in a pH value below 11, see [2]. The concrete mix is called B200 and is self-compacting and contains ordinary Portland cement, densified silica fume, limestone filler, 
superplasticizer, high quality natural fine aggregates and average quality crushed coarse aggregate, see Table 1.

Due to the low amount of cement used, the heat development due to hydration is low, which results is slower maturity. The strength development at early age is slow, but after 28 days the expected cylinder strength is about $42 \mathrm{MPa}$ and about $62 \mathrm{MPa}$ after three months. Several experimental studies of the material properties of the B200 low $\mathrm{pH}$-concrete have been performed and these are presented by [1] and [2].

Table 1 - Material composition of B200, from [2].

\begin{tabular}{lc}
\hline Constituent & $\begin{array}{c}\text { Amount } \\
\left(\mathrm{kg} / \mathrm{m}^{3}\right)\end{array}$ \\
\hline CEM I 42.5 MH/SR/LA & 120 \\
Silica fume (densified) & 80 \\
Water & 165 \\
Limestone filler L25 & 369 \\
Sand 0-8 mm (65\% of aggregates) & 1037 \\
Gravel 8-16 mm (35\% of aggregates) & 558 \\
Glenium 51 & 6.38 \\
\hline & \\
\hline water/cement & 1.38 \\
water/binder & 0.83 \\
water/powder & 0.29 \\
\hline
\end{tabular}

Typically for higher strength concrete, the autogenous shrinkage is relatively high, and especially for the first three months. The high autogenous shrinkage could potentially cause cracking in the dome unless measures were used. The early autogenous shrinkage from one hour to 24 hours after casting was about $0.8 \mathrm{~mm} / \mathrm{m}$, and the additional autogenous shrinkage from 24 hours after casting to 90 days was about $0.2 \mathrm{~mm} / \mathrm{m}$, i.e. resulting in a total autogenous shrinkage after 90 days of about $1.0 \mathrm{~mm} / \mathrm{m}$, according to [2]. Some of this shrinkage will of course be compensated for by a slow casting rate. One of the design requirements for the concrete plug was that it should be considered as stress free after 90 days. This means that the shrinkage during the first 90 days must be considered as free shrinkage, i.e. without restraint, and therefore the concrete plug should release from the rock surface during this time, [3]. Therefore, to avoid the risk of cracking, an advanced cooling sequence was utilized with the intention to break the bond between the concrete and rock.

\section{2.}

\section{THE DOMEPLU FULL-SCALE TEST}

The Dome plug (DomePlu) full-scale test started with excavation of the test tunnel, which was performed early in 2012. The excavation was made with a drilling and careful blasting technique to minimize the excavated damage zone in the rock. The tunnel is horse-shoe shaped with a width of $4.2 \mathrm{~m}$ and a height of $4.8 \mathrm{~m}$ and a total length of about $14 \mathrm{~m}$, see Figure $3 \mathrm{a}$ ) and Figure $3 \mathrm{~b})$. After the excavation was done, wire-sawing was used to excavate a slot in the rock. This slot constitutes the abutment for the concrete dome. The excavation of the slot was made by 
drilling eight $250 \mathrm{~mm}$ cores from the downstream side and eight $250 \mathrm{~mm}$ holes from the upstream side that intersected the previously drilled holes. The holes were inclined to form an octagonal shape after this wire-sawing with a pushing cut was made to create the slot, see Figure $3 \mathrm{~b})$.

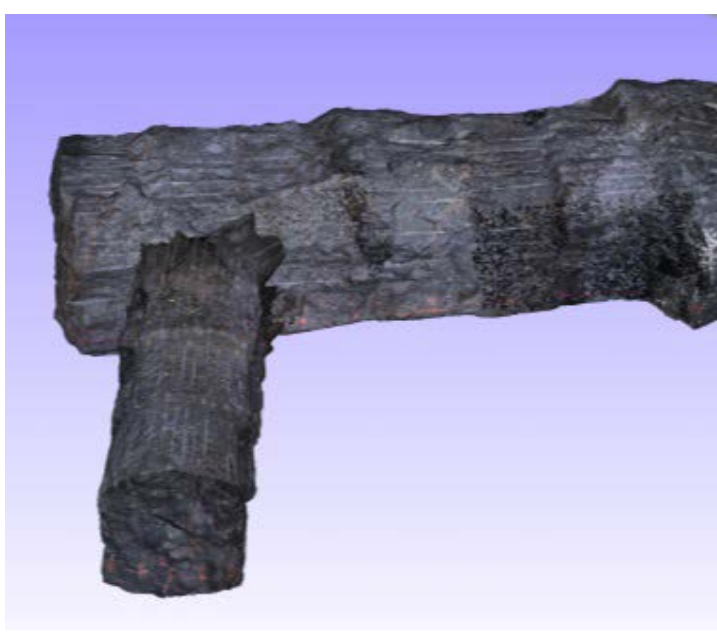

a)

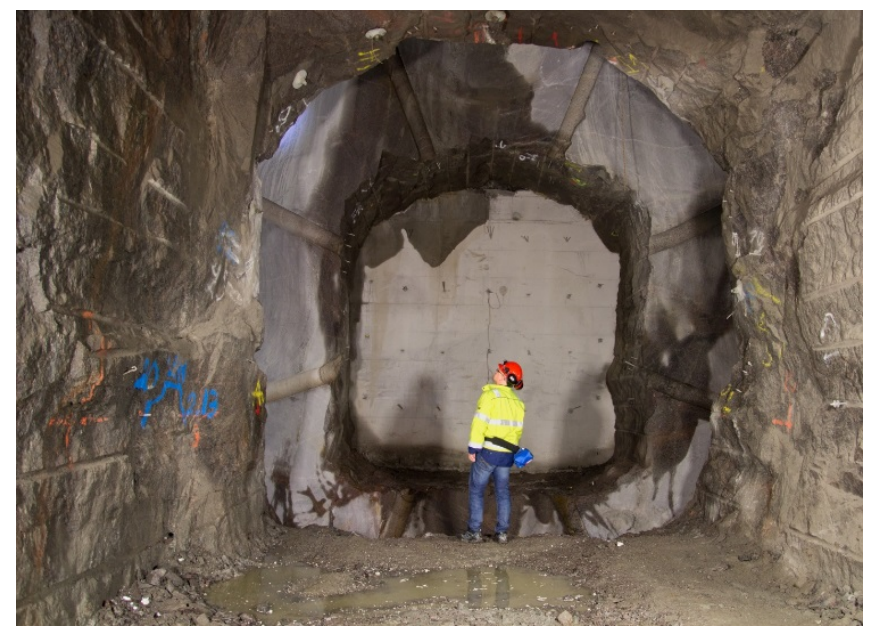

b)

Figure $3-a)$ Illustration of the excavated test tunnel based on laser scanning, b) Photo of the excavated slot, in the photo the project leader Pär Grahm (SKB) is shown.

The plug that was built in the full-scale test deviated to a small extent compared to the reference design of plugs shown previously in Figure 1. The reason for this was that the length of the test tunnel, which was excavated a shorter length compared to the deposition tunnels due to practical reasons, considering that this test was aimed to evaluate the plug. At the end of the excavated tunnel, a concrete wall was cast to ensure a smooth vertical surface for the installation of the backfill bentonite blocks, see Figure 3 b). Thereby, no transition zone as shown in Figure 1 was installed.

After the tunnel excavation was finalized, the different material layers in the plug was installed. From the upstream side, the tested plug consisted of the following layers

- Backfill zone $-100 \mathrm{~cm}$

- LECA Beams - $30 \mathrm{~cm}$

- Macadam filter - $30 \mathrm{~cm}$

- Geotextile

- Bentonite seal - $50 \mathrm{~cm}$

- Concrete beams - $30 \mathrm{~cm}$

- Two-ply geotextile

- Concrete dome $\sim 180 \mathrm{~cm}$ (in the centre)

In the following, only the installation of the concrete dome will be described. The installation of the other material layers is described in detail in [1]. 
Casting of the concrete dome was performed on March $13^{\text {th }}$ in 2013 . The concrete was delivered to the site in Äspö HRL by 13 lorries from the factory in Kalmar. It was highly important that correct properties were achieved of the fresh concrete, especially when using self-compacting concrete, to ensure a successful pour and casting. Therefore, extensive testing was performed on site for each batch of concrete, where slump flow, air content and density were measured onsite. Besides this, 12 cubes were cast at the factory and at the site and these were used to determine the cube strength and the tensile splitting strength.

The estimated time needed for transport was about 2 hours from the factory to the site underground and then additionally 45 minutes were needed for casting. The concrete was pumped through a pipeline to the concrete dome plug. The casting of the dome was made with a maximum casting height of $100 \mathrm{~cm}$ per hour which resulted in a total time for casting of approximately 10 hours.

The concave downstream shape of the dome and the use of self-compacting concrete resulted in a rather complex formwork designed to carry the full hydrostatic pressure, as seen in Figure 4 a). On the upstream side, the concrete beams act as formwork and a geotextile had been installed to prevent bond between the concrete dome and the concrete beams, as seen in Figure $4 \mathrm{~b}$ ).

Cooling pipes were installed for cooling of the concrete dome. The cooling pipes were made of copper with a diameter of $\phi 25 \mathrm{~mm}$, and consisted of three separate sections where each section had a length of $80 \mathrm{~m}$. Since there was no reinforcement in the concrete dome, a supporting steel scaffolding was installed to carry the self-weight of the cooling pipes, as seen in Figure $4 \mathrm{~b}$ ). A design criterion for the steel frame was that it should not be attached to the rock in both the top and bottom, i.e. so that it could cause restraint forces in the concrete dome due to shrinkage. One cooling machine of at least $20 \mathrm{~kW}$ was needed for the cooling. However, since the cooling was vital for the construction, a redundant (backup) cooling machine was also placed on site, if the first one would fail for some reason. The flow of the cooling media was controlled by temperature where the allowed difference between inlet and outlet temperature was defined as $2{ }^{\circ} \mathrm{C}$.

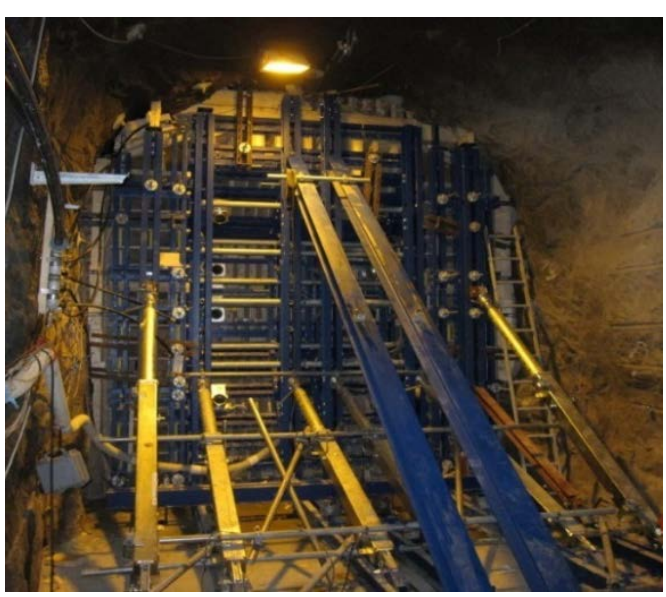

a)

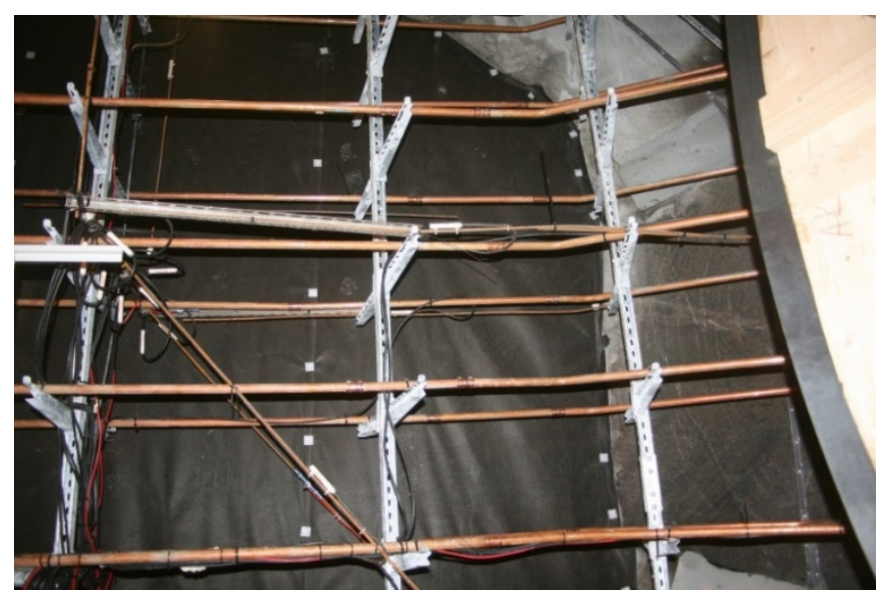

b)

Figure 4 - Photos from construction of the dome plug, a) formwork, b) cooling pipes and their scaffolding. 
Considering that the concrete dome is unreinforced the intention was to allow for free shrinkage during the first three months. This would be achieved by an advanced cooling procedure, where the concrete was cooled during hardening (stage A) and when sufficient strength has been developed, the intention was to cool the concrete significantly to break the bond between concrete and rock (stage B). This procedure would thereby allow for free shrinkage and after about three months the concrete dome would be cooled once again (stage C) to make it shrink as much as possible to allow for contact grouting between the dome and the rock surface. The cooling during contact grouting would also result in thermal pre-stressing of the dome when the cooling was ended. The temperature in the tunnels was about $14^{\circ} \mathrm{C}$ and the temperature in the inlet of the cooling pipes was at most reduced to $1^{\circ} \mathrm{C}$. The temperature in the concrete varied and was naturally higher than this, as later presented in Section 4.2. The cooling procedure of the dome is illustrated in Figure 5, where the three stages A, B and C are illustrated.

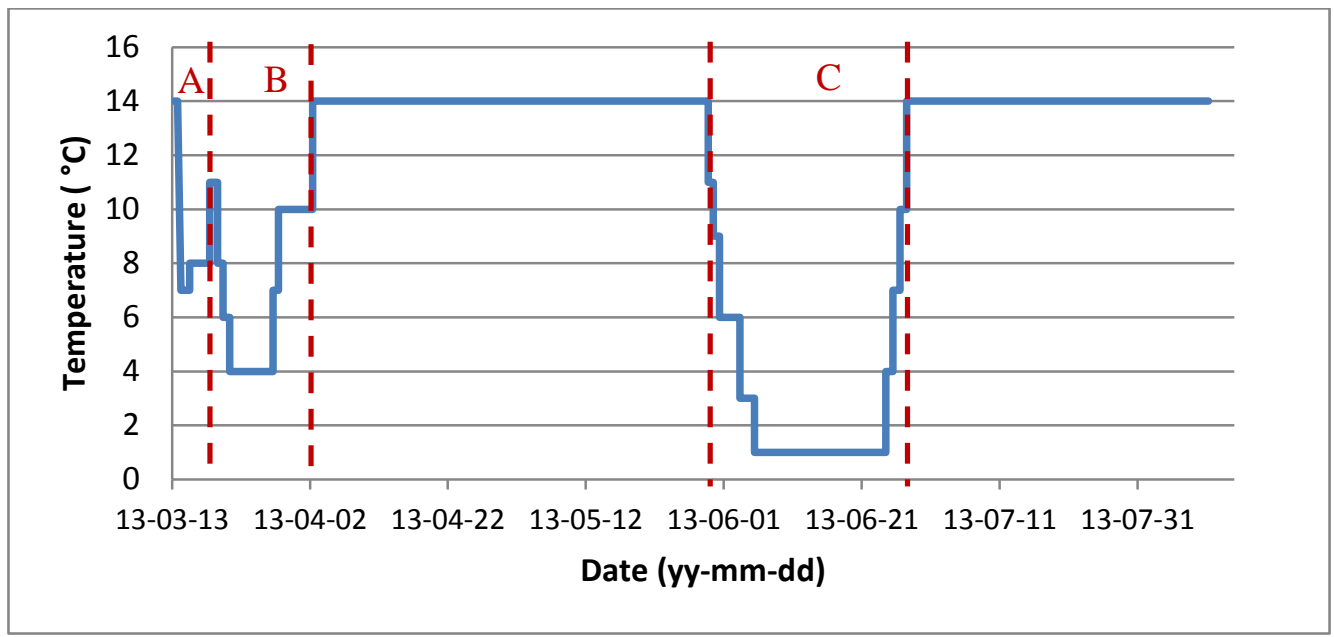

Figure 5 - Illustration of inlet temperature in the cooling pipes during the cooling procedure, with the three stages (A) cooling during hydration, (B) cooling to force the dome release from the rock and $(C)$ cooling during contact grouting plug used in the full-scale test.

In the wire sawn slot, grouting pipes were installed as shown previously in Figure 2. The purpose of the grouting tubes was to ensure water tightness of the dome. In addition, the thermal pre-stress of the dome will minimize the risk of cracking and thereby lead to reduced leakage. After about three months, contact grouting was performed. The purpose of the contact grouting was to seal gaps that had occurred between the concrete dome plug and the surrounding rock. Due to the high amount of shrinkage during the first 90 days according the experiments and the thermal cooling of the concrete dome plug, it was intended to create a gap between the rock and concrete plug. According to [3], the estimated gap due to shrinkage at the time of grouting would be about $3.7 \mathrm{~mm}$ in the top of the dome plug, under the assumption that the plug has released from the rock. In addition, since cooling was performed prior to contact grouting, the gap between concrete and rock was planned to increase even further up to $4.2 \mathrm{~mm}$. First the inner tube on the upstream side was grouted and after this the outer tube, i.e. on the downstream side. Both were performed on the same day, June $11^{\text {th }}$, 2013. In the first stage, a total of 105 litres were used and the pressure was stable and ended at 10 bars. During the second stage, i.e. grouting of the outer tube, when about 42 litres of grout had been used, a small area with leakage of grouting could be detected near the top of the dome. The total amount of grout was about 93 litres where the final pressure was 10.7 bar. The third and final grouting stage was performed about one week after the first two. In the third grouting stage, the centre tube was grouted with a total of 406 litres, ending up with a final pressure of $61 \mathrm{bar}$, i.e. $6 \mathrm{MPa}$, with a pressure increase of $10 \mathrm{bar} / \mathrm{min}$. During the grouting of the last tube, no leakage was detected by 
the workers on site. The grouting pressure was maintained for 30 minutes before the grouting was ended.

A total volume of 654 litres was thereby used for grouting, which is almost three times as much as needed to fill the gap between concrete dome and the rock according to a simplified estimation of the expected gap. It is thereby likely to assume that grout also may have filled voids or cracks/fractures within the rock and or within the concrete dome, such as between cooling pipe and concrete dome. It is also possible that the top of the dome was not filled completely during casting or that grout may have filled voids in between the concrete beams.

\section{$2.3 \quad$ Pressurization}

The swelling pressure acting on the dome is expected to be about $2 \mathrm{MPa}$, but this develops over many years if only natural inflow of water occurs. The purpose of the test was to subject the plug to its serviceability loads. Therefore, to decrease the time needed for the experiment, a pressurization system was used to control the water pressure in the filter of the plug. Owing to the pressurization of water, it was possible to increase the rate of saturation of the bentonite seal so that the maximum swelling pressure should be reached during the test period.

The pressurization of the plug started initially with only natural inflow of water. After about 0.8 MPa of water pressure was reached in December 2013, the pumps started which continuously increased the water pressure until $4 \mathrm{MPa}$, i.e. a hydraulic head of $400 \mathrm{~m}$, was reached. The intention was to increase the water pressure up to $7 \mathrm{MPa}$, however due to the conditions of the surrounding rock at the experimental site it was not possible. After the water pressure had been increased to about $3 \mathrm{MPa}$, a significant leakage in the rock occurred in the adjacent tunnel, about $15 \mathrm{~m}$ from the plug. Water leakage through rock fractures had been recognized as one major project risk since the rock at Äspö HRL is significantly fractured in general. Due to the encountered rock fracture, by-passing the plug, it was decided to limit the water pressure in the plug to $4 \mathrm{MPa}$ and perform continuous measurements of the observed leakages at this level. This pressure could successfully be maintained by the water pressurization system for about three years. The pressurization curve from the full-scale test is shown in Figure 6.

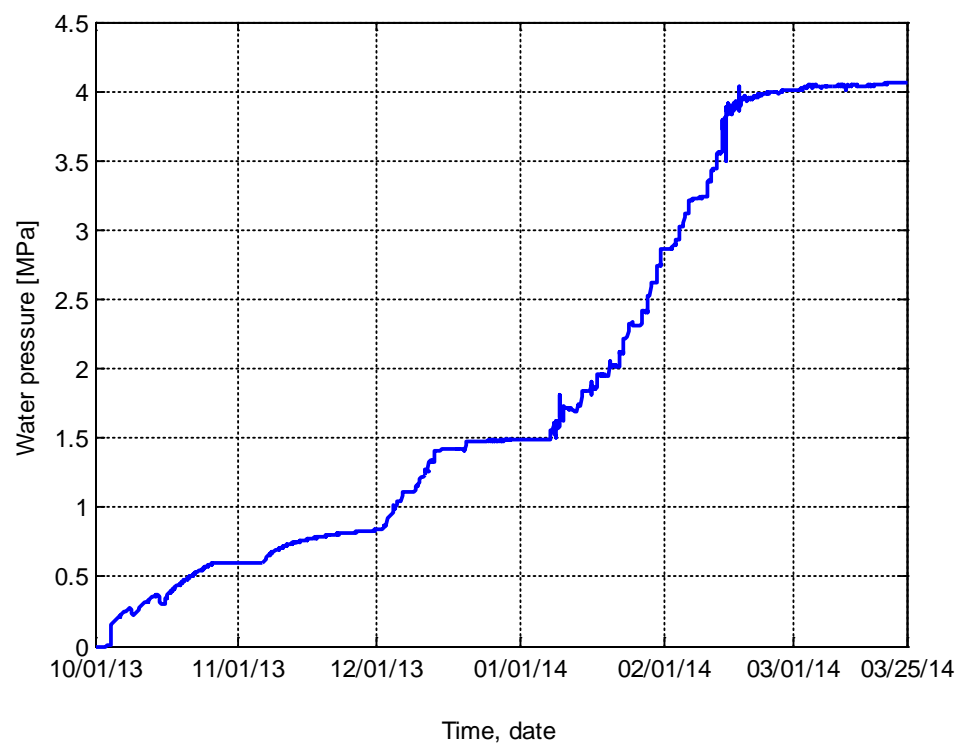

Figure 6 - Pressurization sequence of the plug, where the pressure was increased to $4 \mathrm{MPa}$. 


\section{3.}

\section{INSTRUMENTATION PROGRAM}

The full-scale test of the plug was instrumented with several types of sensors. However, in this paper, only the sensors used to monitor the concrete dome are described.

\section{1}

\section{Monitoring of the concrete dome}

The concrete dome was instrumented with several sensors, where most of them were embedded inside the concrete dome. Some sensors were only used for a shorter period, such as measuring the pressure on the formwork, while the others were used to monitor the behaviour from the hardening process and continued for about five years.

The different types of recordings were; temperature in the concrete dome and the ambient air, strain in the concrete dome, displacement sensors measuring the displacement of the dome and the joints between concrete and rock. In total, the response of the concrete dome was measured with 62 recorded signals where the following types of sensors were used [3]:

- 5 pressure sensors (Wika S11) - pressure on the formwork

- 6 joint meters (TML type KJA-A) - relative displacement between concrete and rock

- 3 LVDT (HBM type WA) - displacement of the concrete dome

- 14 strain gauges (TML type KM-AT) - strain and temperature in the concrete dome

- 10 strain gauges (TML type KM-A) - strain in the concrete dome

- 4 strain gauges (Geokon 4200) - strain and temperature in the concrete dome

- 2 temperature sensors (PT 100) - ambient air temperature

In this paper, the focus is on evaluating the early age behaviour and the response during initial pressurization. Therefore, all results from this full-scale test will not be presented in this paper. In Figure 7, a photo of installed strain gauges and cooling pipes is shown in addition to a sketch illustrating the placement of sensors.

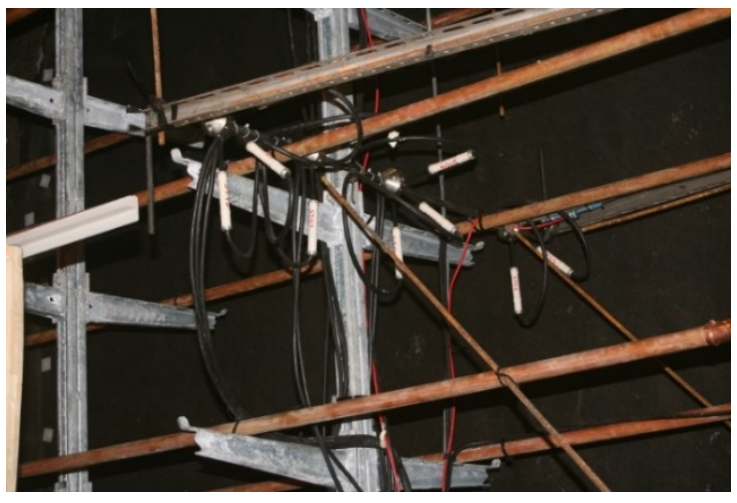

a)

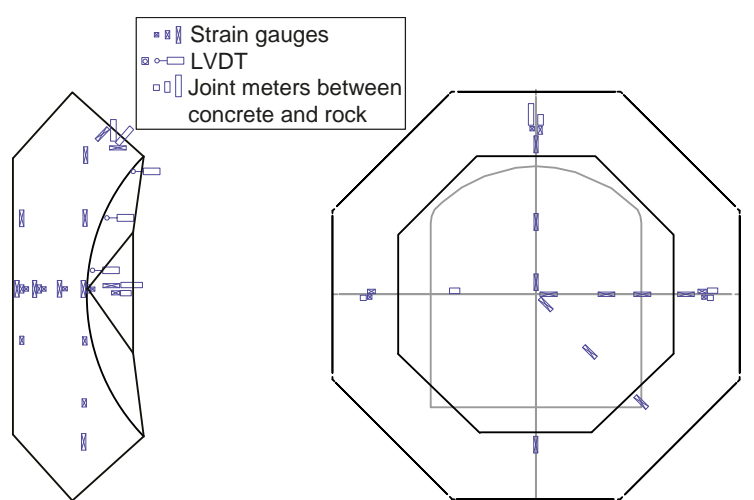

b)

Figure 7 - Installed sensors, a) strain gauges in the centre, b) placement of sensors.

Numerical analyses had been used before the full-scale test to determine suitable measuring ranges and to select the placement of the sensors, see [1]. The structural response from shrinkage and water pressure is expected to be the same regardless which quarter of the dome the sensors were placed in as long as the sensors are placed at the same depth and radius, due to 
symmetry of the dome. However, due to the gravity force, largest stresses will occur in the upper half of the dome due to bond between concrete and rock. Therefore, the instrumentation of the concrete dome was primarily made in one quarter (in the upper half) of the concrete dome. In the monitoring program for the concrete dome, some redundancy was included to increase the probability that the behaviour would be measured even if some sensors failed. This was achieved both by using the symmetry and placing sensors at positions that were expected to give similar results (i.e. placed at similar radius and depth) and in addition of using sensors from different manufacturers.

The following instrumentation loggers were used for the different sensors;

- HBM Spider8 - For sensors measuring the pressure on the formwork

- Gantner Q.bloxx A104 - For Geokon strain gauges (including their temperature signals). A Vib Wire-108 module was used to convert the signal from the sensors

- Gantner Q.bloxx A106 - For TML strain gauges, joint meters and LVDT sensors

- Gantner Q.bloxx A107 - For ambient air temperature sensors and thermocouple signal of TML strain gauges

The sampling rate in the measurements of the pressure on the formwork was one reading each minute and for all other measurements a sampling rate of one reading every five minutes was used.

\section{2}

\section{Instrumentation}

In total, 28 strain gauges were embedded in the concrete dome with the intention to capture its behaviour from hardening until the test was ended. The placement of all embedded strain gauges is illustrated in Figure 8. Sensors were placed at four depths in the centre of the dome and in three directions to capture the distribution of strain. In addition, several strain gauges were placed close to the interface between concrete and rock. Almost all strain gauges were placed on shorter reinforcement bars that were mounted on the cooling pipes, except for the strain gauges closest to the rock. In this case it was not possible to attach these to the cooling system, so instead reinforcement bars were installed in the rock on which the strain gauges were attached. The concrete cover was at least $400 \mathrm{~mm}$ for the sensors closest to the surfaces to minimize the risk of the sensors being subjected to high water pressure.
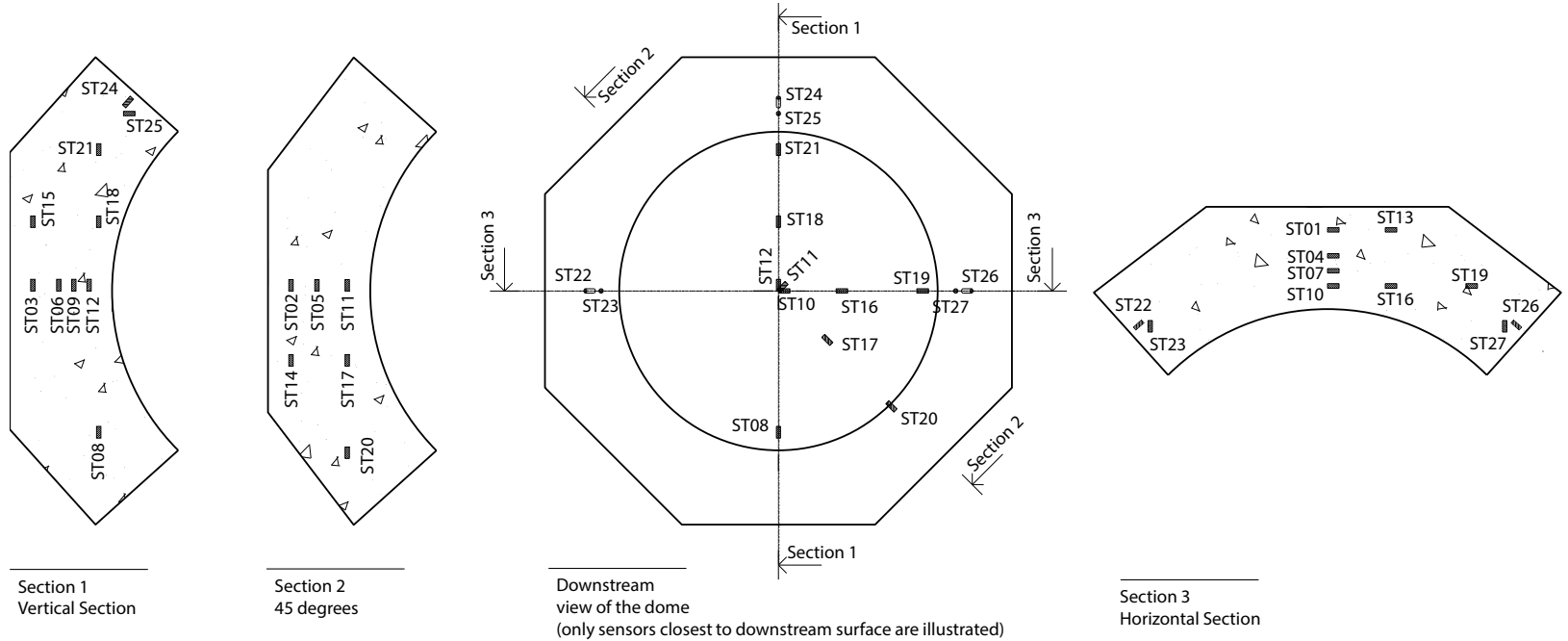

Figure 8 - Placement of installed strain gauges. 
Joint meters were installed to measure the relative displacement between the concrete dome and the rock. In total, 6 joint meters were installed; two sensors each at the left- and right-hand side and two in the top. All these sensors were drilled into the rock at the downstream side of the slot, where one was placed perpendicular to the rock surface and the other one was placed vertically (in the top) or in the tunnel axis direction (left- and right-hand side). The intention of these sensors was to observe if the concrete dome released from the rock. It was expected that the concrete dome would release from the rock during the second cooling stage (B), and that the downstream side would be compressed when the dome was subjected the water pressure.
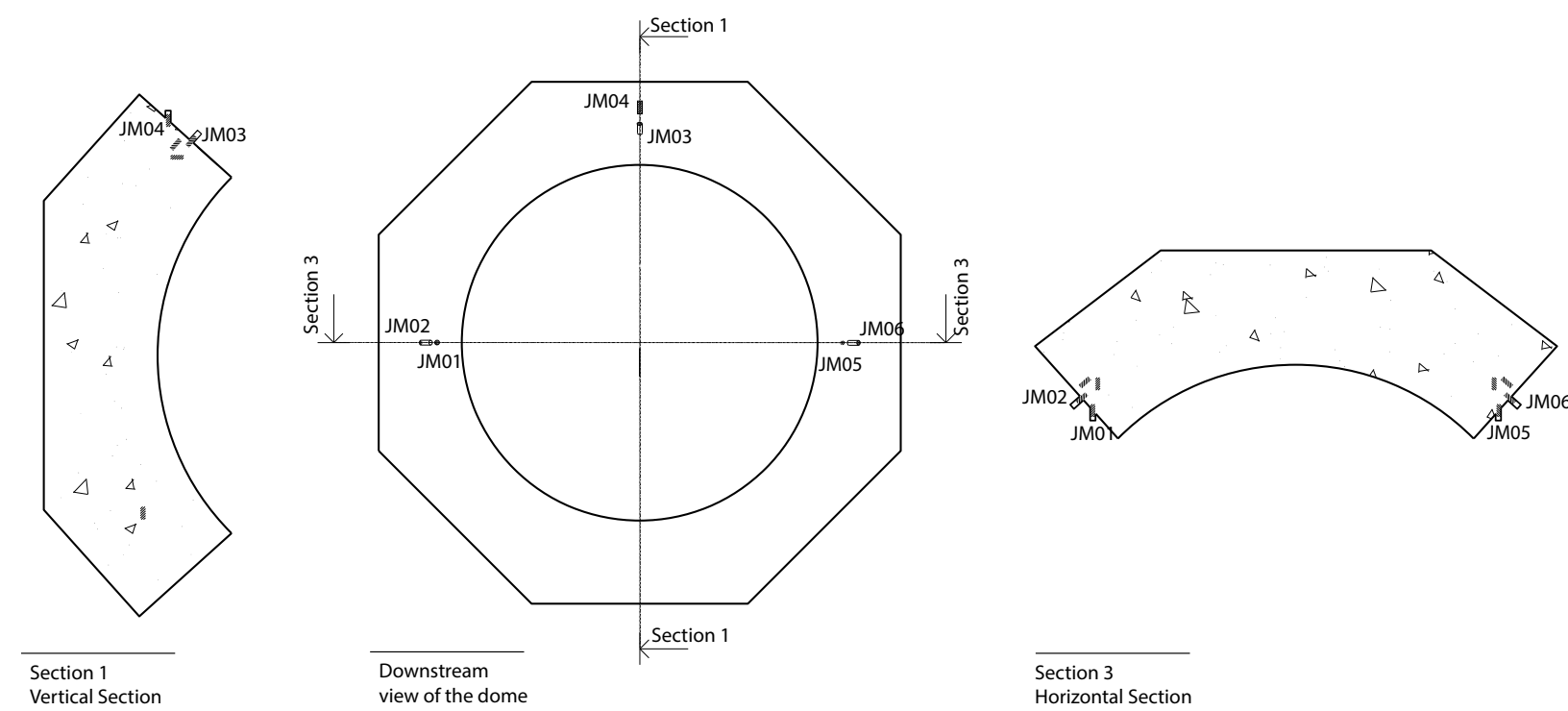

Figure 9 - Placement of installed joint meters gauges.

\section{2}

\section{Signal processing the measured data}

All sensors have been temperature compensated based on the difference in thermal expansion of the sensors and the concrete. This is described in detail in [4]. In addition, all measured signals have been subjected to signal processing to remove effect from background noise and from spurious voltage impulses that occurred. All signal processing has been performed with the signal processing toolbox in Matlab by using smoothing filters. For the Geokon sensors, local regression using weighted linear least squares and a $1^{\text {st }}$ degree polynomial models that assigns lower weight to outliers (denoted "rlowess") were used primarily to reduce the influences of the spurious voltage impulses. For all other signals, the filtering was made with Savitzky-Golay, a generalized moving average filter from unweighted linear regression, primarily to attenuate the background noise. More information about the signal processing can be found in [4].

4.

RESULTS

\section{1}

\section{Pressure on the formwork during concrete hardening}

The pressure on the formwork was measured at five locations over the height of the form/dome. The sensors were numbered from 1 to 5 based on their height above the ground, meaning sensor no 1 was at the bottom and sensor no 5 was close to the top. In Figure 10 a), the pressure is shown as a function of time, measured at each sensor and in Figure 10 b) the same result is 
presented in a 3D plot (height, pressure and time). As can be seen, the maximum pressure at each location of the sensors occurs a few hours after the level of concrete reached that position. This means that the hardening of concrete in the bottom started before the whole plug was cast. Thereby, the maximum theoretical hydrostatic pressure of $160 \mathrm{kN} / \mathrm{m}^{2}$ (at the bottom) never occurred. Instead the maximum pressure measured close to the bottom was approximately 25 $\mathrm{kN} / \mathrm{m}^{2}$. The maximum form pressure was typically $35 \mathrm{kN} / \mathrm{m}^{2}$ measured at all sensor positions. However, there was a significant increase measured at the sensor in the top where it increased from about $30 \mathrm{kN} / \mathrm{m}^{2}$ to a maximum of approximately $80 \mathrm{kN} / \mathrm{m}^{2}$ for a period of four minutes. This was however after casting was completed. According to the staff at site during casting, the contact grouting tubes were pressurized at the end of casting to cleanse the tubes. This pressure impulse, is likely a result of this action.

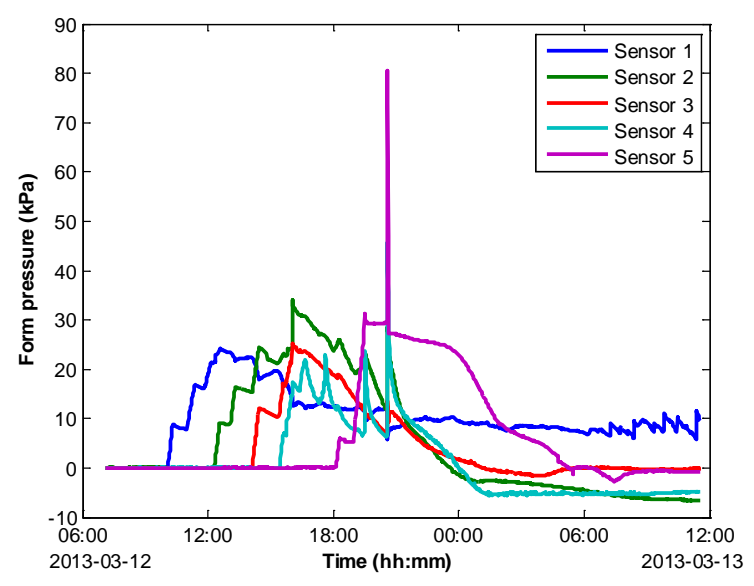

a)

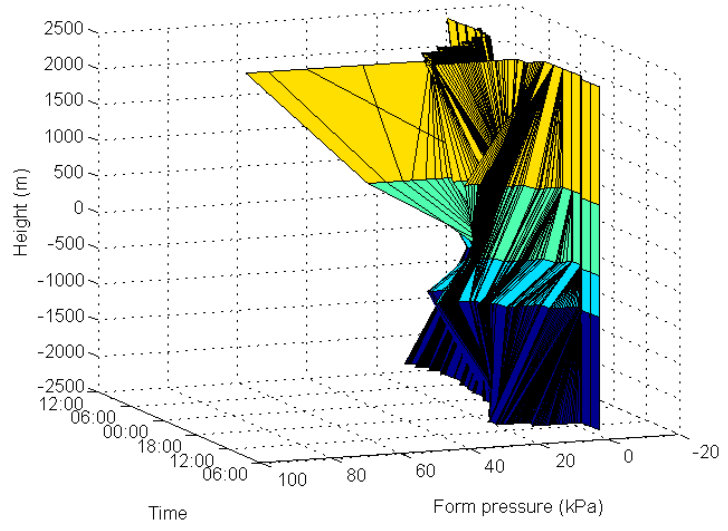

b)

Figure 10 - Recorded pressure on the formwork.

\section{2}

\section{Temperature development during concrete hardening}

The temperature in the ambient air in the tunnel varied typically between 13 and $15^{\circ} \mathrm{C}$ during the measuring period. The initial temperature for all batches of concrete was about $10^{\circ} \mathrm{C}$ prior to casting. After the hydration of the concrete had started, the cooling pipes started to reduce the temperature in the concrete. The cooling sequence was conducted in smaller steps as shown in Figure 5. The aim of the concrete cooling during hydration (stage A) was to ensure that the temperature in the dome was less than $20^{\circ} \mathrm{C}$. As it can be seen in Figure 11, the maximum temperature in the concrete was slightly below $18^{\circ} \mathrm{C}$ during hydration. After this, the cooling stage $\mathrm{B}$ was performed, intended to break the bond between concrete and rock. During this stage, the temperature in the cooling pipes was reduced to $4{ }^{\circ} \mathrm{C}$ and maintained at this level for 6 days. This resulted in a temperature in the concrete between 6 and $10^{\circ} \mathrm{C}$. After this the temperature increased as the cooling equipment was turned off.

Finally, after about three months, the cooling system was used once again to cool the concrete dome as much as possible to allow for effective contact grouting. During this cooling stage (C), the inlet temperature in the cooling pipe was reduced to $1^{\circ} \mathrm{C}$ to create a large thermal prestressing of the concrete dome, i.e. to introduce compressive forces into the dome after the cooling was completed. The measured temperature during the cooling period prior to the contact 
grouting (stage $\mathrm{C}$ ), decreased to a minimum of $3{ }^{\circ} \mathrm{C}$ and was about $8{ }^{\circ} \mathrm{C}$ as maximum, as seen in Figure 11.

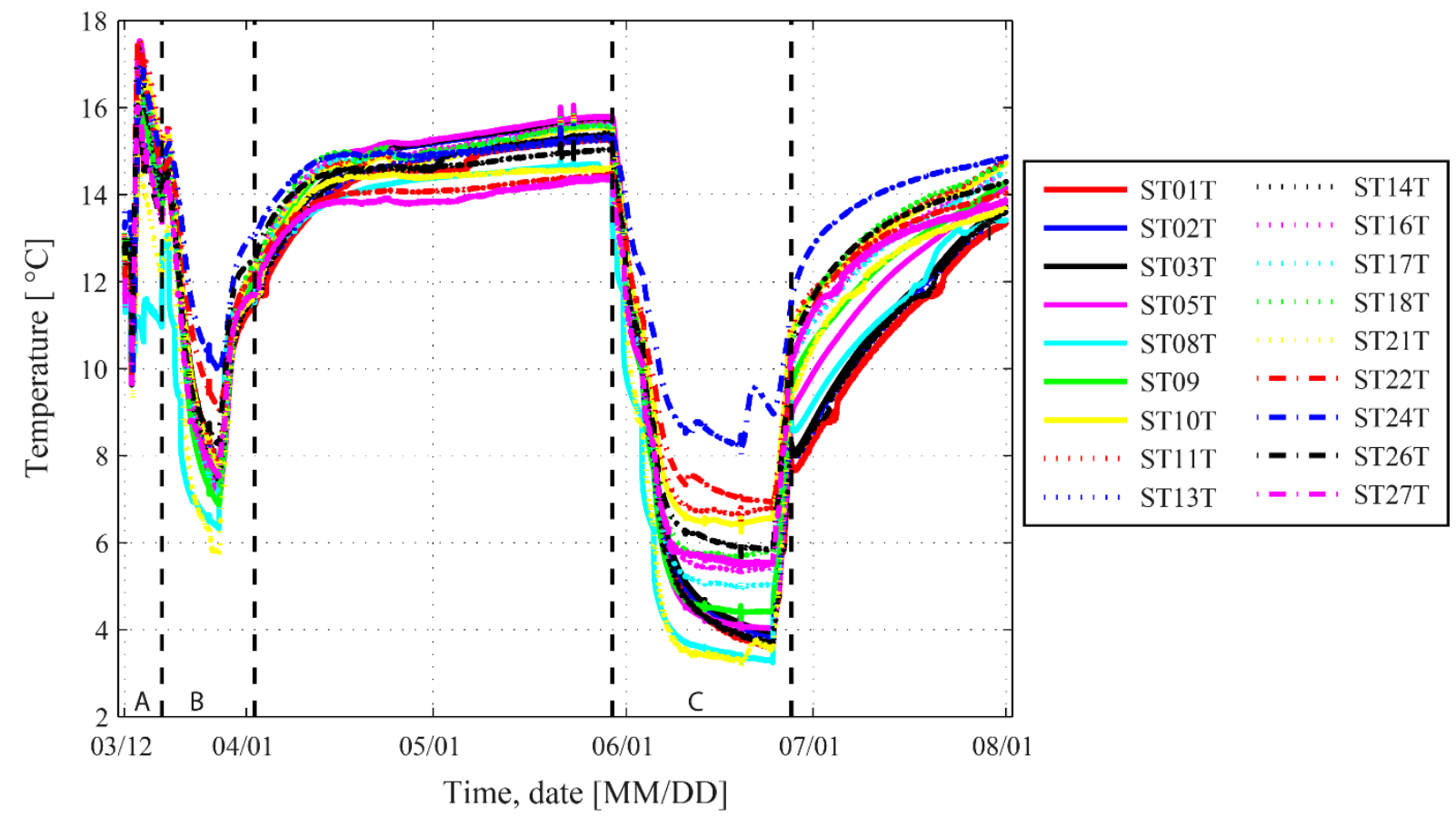

Figure 11 - Recorded temperatures in the concrete during the first five months.

The advanced cooling sequence had worked and no visible cracks could be detected in the concrete dome. However, whether the concrete dome had released from the rock or not during cooling stage B was uncertain. Therefore, different methods were used to evaluate this based on the measurements as shown in the following sections.

\section{3}

\section{Relative displacement between concrete and rock}

The joint meters measured the relative displacement between concrete and rock at six locations, as previously shown in Figure 9. The results up to the point after contact grouting is shown in Figure 12. As can be seen in Figure 12, the joint meters show small relative movement between concrete and rock which indicates no direct crack opening during the first stages. The maximum relative displacement is $0.1 \mathrm{~mm}$ during cooling prior to grouting (stage $\mathrm{C}$ ). If the concrete dome had released from the rock, a relative displacement of about $4.2 \mathrm{~mm}$ had occurred according to [3]. This shows that the concrete dome did not release from the rock on the downstream side of the slot, at least not at these locations. The relative displacements are in general so small, and most likely corresponds to elastic strains in the concrete. However, all joint meters show a slightly larger value after grouting than before, which indicates that at least some parts of the slot have been grouted. The largest difference before and after grouting is seen on JM05 which measures the relative displacement in the tunnel axis and is located on the right-hand side (viewed from the downstream side). 
Nordic Concrete Research - Publ. No. NCR 58 - ISSUE 1 / 2018 - Article 4, pp. 55-75

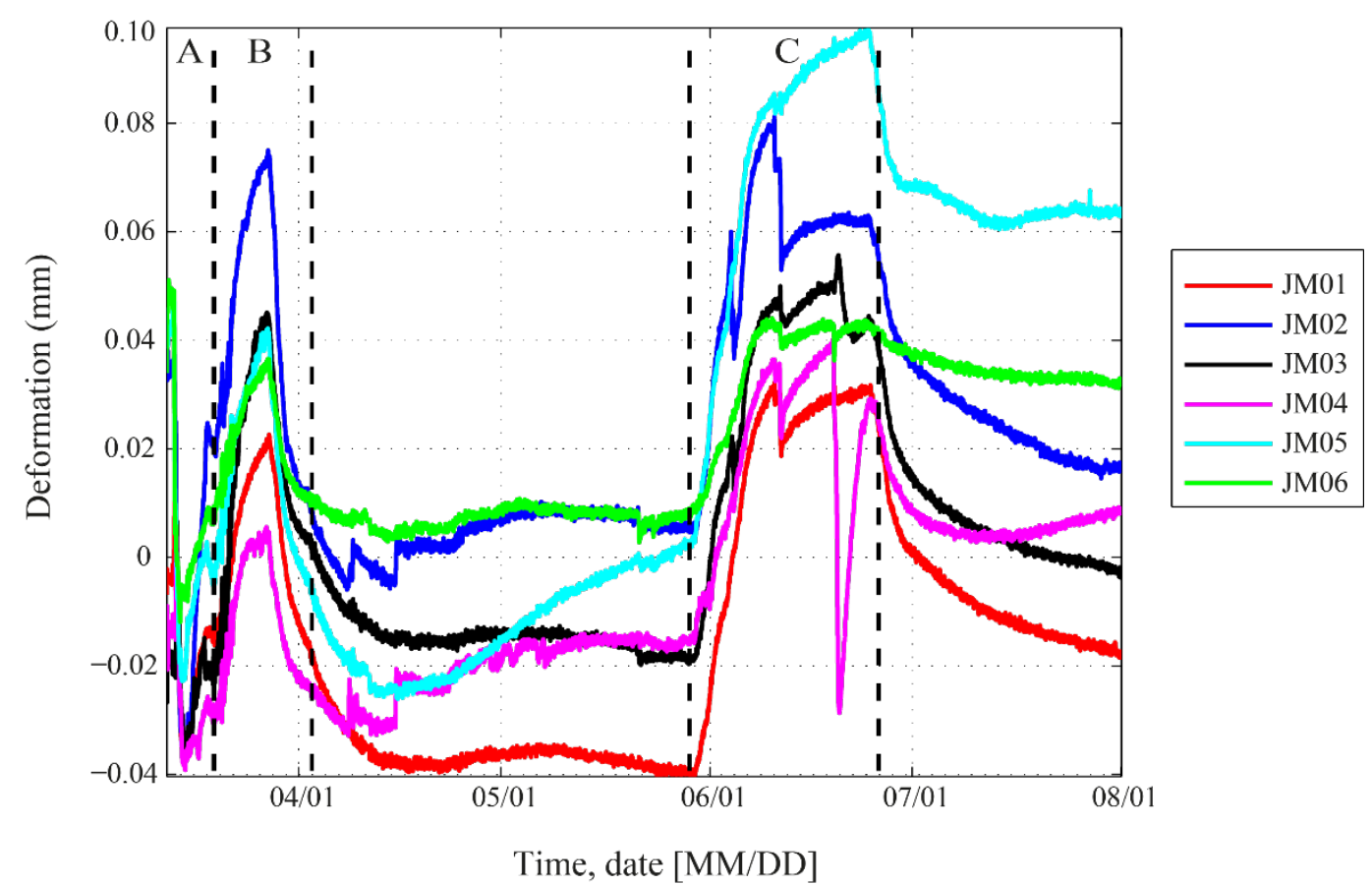

Figure 12 - Variation in relative displacement at the interface between concrete and rock.

\section{4}

\section{Induced strains in the concrete}

The difficulty with analysing the induced strains in the concrete is to determine at which point sufficient bond between concrete and the sensors has been reached. During the first hours after pouring the concrete, the concrete behaves completely plastic and no reliable strains can be measured. After this, as the hydration initiates and the concrete strength starts to develop and due to the increased temperature from the hydration, compressive stresses occur in the concrete. When the heat generated by the hydration reduces which result in decreased temperature in the concrete, where tensile stresses develop, [5].

In the full-scale test, two different type of strain gauges were used. The strain gauges with larger flanges (Geokon 4200) at the ends, were significantly easier to evaluate regarding the early age behaviour since they quite early recorded reliable strains in the concrete. In Figure 13, the development of strain from one of these sensors is shown as an example for the early age strain development in the dome. In the figure, the corresponding measured temperature at this sensor is also presented. In the figure, the graph is presented from the start of casting (at 07:00 in the morning). The presented sensor is however located in the centre of the dome and hence was not embedded in concrete until about seven hours after casting begun.

For the other strain gauges, with smaller flanges it was much more difficult to capture the early behaviour since several sudden changes in strain occurred in these signals during the casting and early in the hydration process. Methods to find suitable zero-reference level for the strain gauges used in case have been presented by [3] and [6]. The determination of the zero-reference value is, however, only important for obtaining the absolute value of the strain and to predict induced stresses. In this case, it is more interesting to find the influence from the advanced cooling and to quantify the effect from the thermal pre-stress. Thereby, to achieve this only the relative difference of the strain before and after the third cooling stage (stage C) as shown in Figure 14 should be considered, which is described in Section 4.5. 

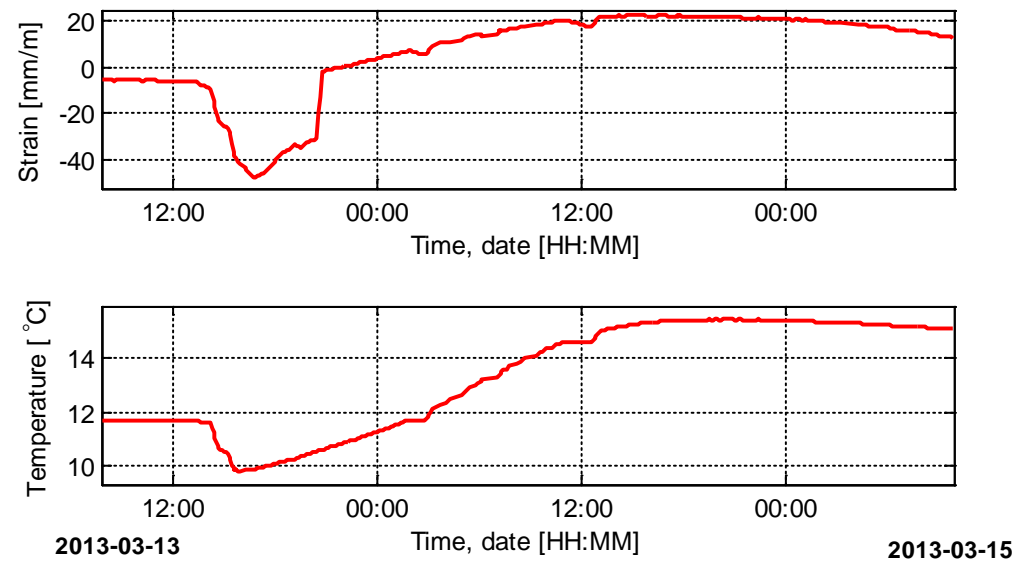

Figure 13 - Early strain/stress development in concrete. Measured strain development in the dome plug with a Geokon sensor (top), temperature development from the same Geokon sensor (bottom).

Two of the strain gauges failed during the third and final grouting stage. The two strain gauges that failed (ST23 and ST25) were placed adjacent to the joint meters (JM01 and JM03). As it can be seen in Figure 15, these sensors were installed on reinforcement bars drilled in to the rock. However, these reinforcement bars were placed close to the centre tube that was grouted in the final grouting stage. It is therefore believed that the grout travelled along the reinforcement bar up to the strain gauges and the high grout pressure of $6 \mathrm{MPa}$ destroyed these gauges.

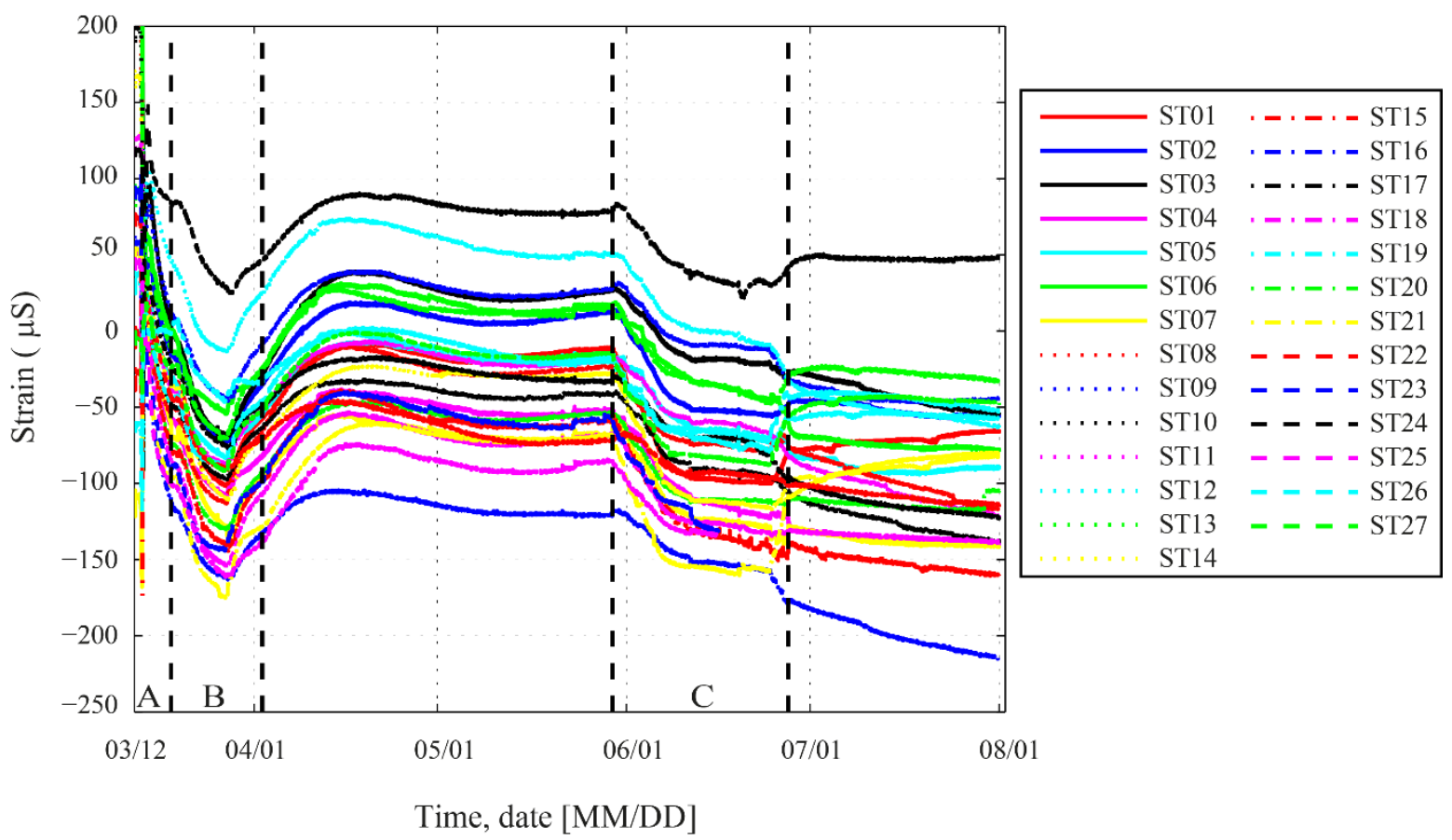

Figure 14 - Variation in measured strain based on all strain gauges. 


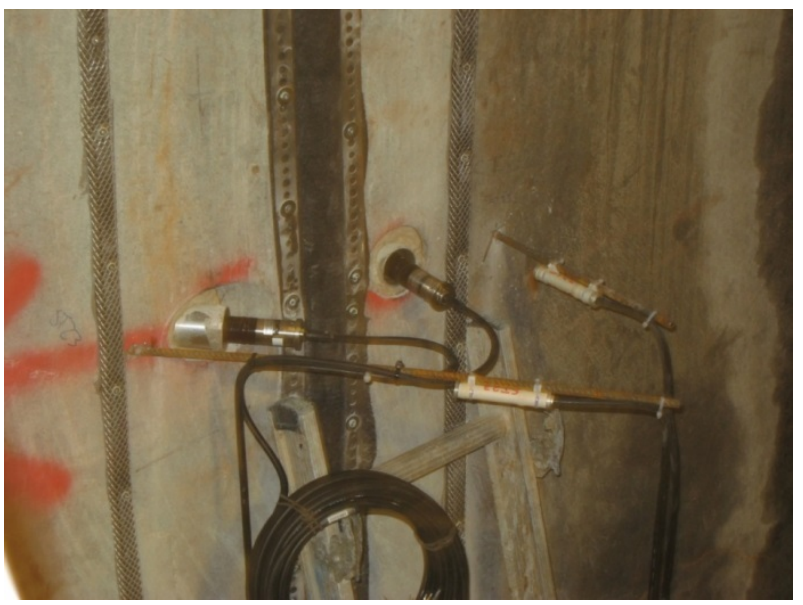

a)

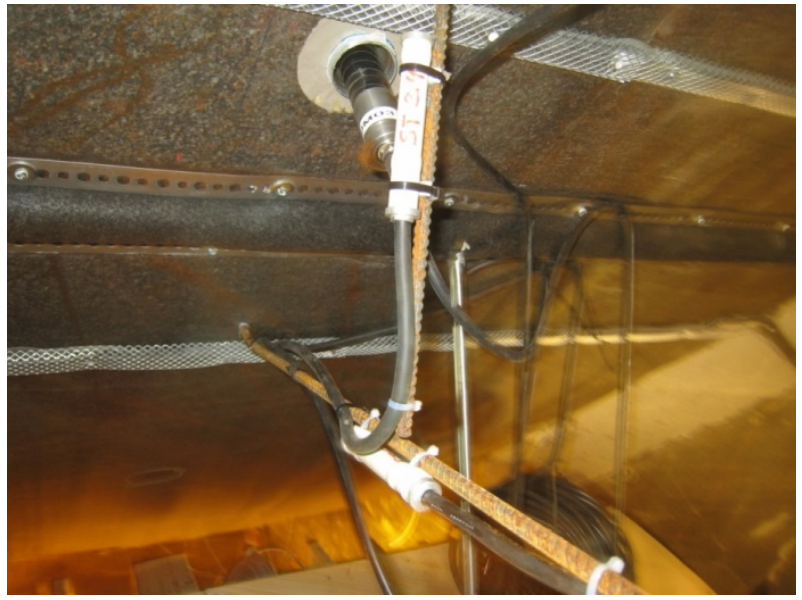

b)

Figure 15 - Photos of strain gauges that failed during the third grouting, a) strain gauge ST23 and b) ST25. Also seen in the photo: the installed joint meters, a) JM01 and JM02 and b) JM03 and JM04.

\section{5}

\section{Effect of the thermal pre-stress}

To estimate the effect from the thermal pre-stress, the relative difference in strain before and after cooling stage C) was analysed for all strain gauges. The time points for the start and stop of the third cooling cycle was illustrated with two black lines in Figure 14. Here the strain difference has been multiplied with the elastic modulus of concrete (33.9 GPa according to [2]) to calculate the compressive pre-stress. The calculated compressive stresses induced due to grouting is presented in Figure 16 a). As seen in the figure, the thermal pre-stress (i.e. compressive) varies from about 0.5 MPa to $3.5 \mathrm{MPa}$ in the concrete dome. It should be noted that the two strain gauges that failed during grouting are shown as zero stress in the figure.

If no grouting could be inserted between the concrete dome and the rock, then the strain would be identical before and after. For a case without bond between the concrete and rock, the full temperature reduction from cooling would result in thermal pre-stress. Here, the temperature difference is based on the difference in temperature for each sensor between maximum temperature during hydration (between 15 and $18{ }^{\circ} \mathrm{C}$ ) and minimum temperature during cooling prior to contact grouting (between 3 and $8{ }^{\circ} \mathrm{C}$ ). The maximum temperature during hydration is considered as the strain free temperature for the concrete. This is denoted as the maximum thermal pre-stress and is shown in Figure $16 \mathrm{~b}$ ). Considering that the temperature varies in the concrete dome to some extent, this results in a variation in maximum theoretical thermal prestress between 3 and $4.5 \mathrm{MPa}$. 


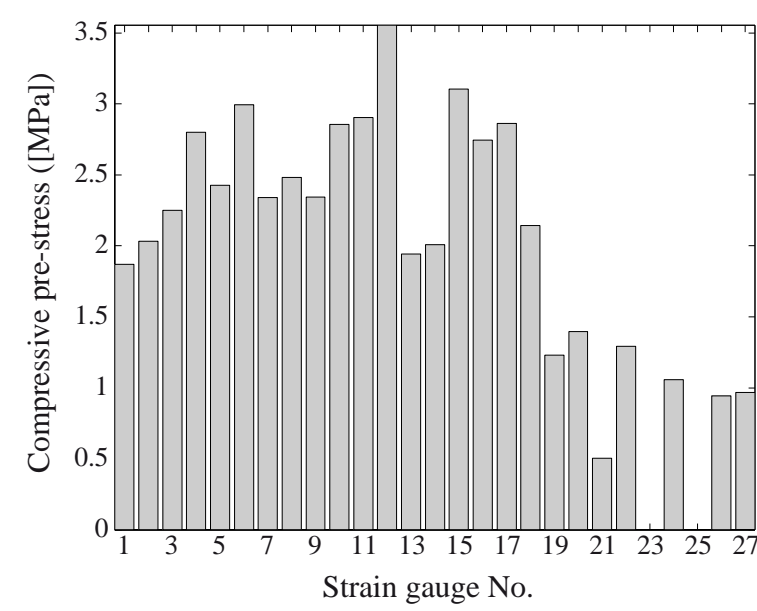

a)

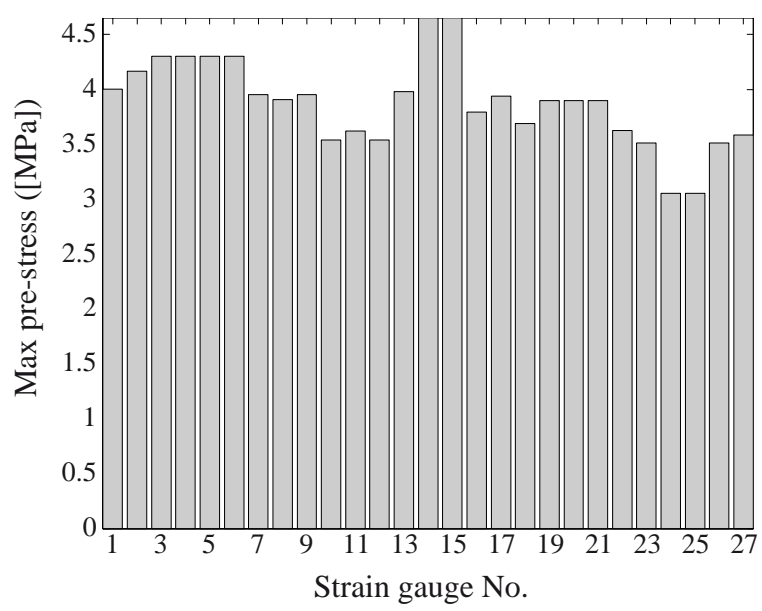

b)

Figure 16 - Calculated effect from the thermal pre-stress during grouting, a) induced compressive strain based on the strain gauges, b) maximal stresses due to the variation in temperature.

Finally, the ratio between the obtained strain difference before and after grouting (Figure $16 \mathrm{a}$ ) and the maximum thermal pre-stresses (Figure $16 \mathrm{~b}$ ) indicates the degree of achieved pre-stress in the dome. By calculating the relative ratio of the induced pre-stress, the results are no longer dependent on the estimated elastic modulus of the concrete and is thereby only dependent on the measured quantities. It can be seen in Figure 17 that one sensor gives 100\%, i.e. where the obtained pre-stress is equal the theoretical maximum. This sensor is denoted ST12 and is mounted in the centre of the dome, about $400 \mathrm{~mm}$ from the upstream surface and measures in the vertical direction. The two sensors close to this, ST10 and ST11 also show high utilization of pre-stress, about $80 \%$ of the maximum theoretical value. In common for the five sensors, that show highest achieved relative pre-stress, is that all are mounted on the upstream side of the dome. Most of the strain gauges show relatively low pre-stress compared to the theoretical maximum where the average utilization is $53 \%$. Thereby, based on the calculated effect of thermal pre-stress it can be concluded that the dome plug had partially released from the rock and it is likely that the upstream side of the slot released to a greater extent than the downstream side (i.e. where the joint meters are located). 


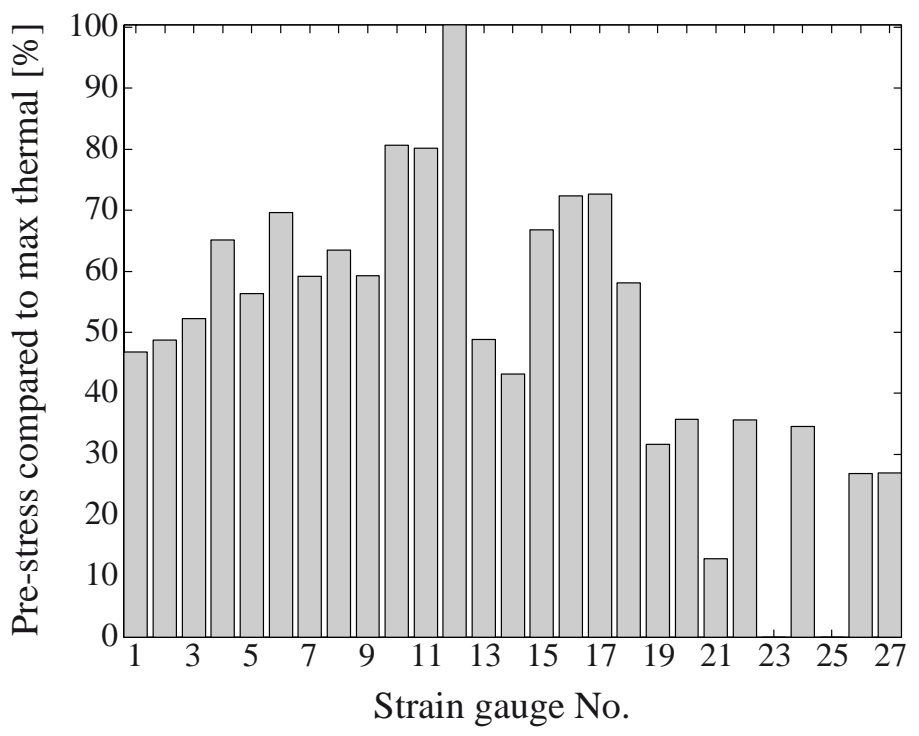

Figure 17 - Achieved pre-stress compared to maximum thermal stress.

\section{6}

\section{Pressurization 4 MPa and long-term behaviour}

As shown previously, the pressurization of the plug was performed to a water pressure of 4 $\mathrm{MPa}$. When the water pressure reached about 3.5 MPa, a significant change for the two sensors in the top of the dome (JM03 \& JM04) occurred as seen in Figure 18. This is likely caused by the dome releasing on the upstream side of the slot and thereby all loads are carried by to the downstream side of the slot in this region. Thereby, the joint meters were compressed and stopped recording reliable displacements when it was compressed beyond its measuring range. A water pressure sensor had been installed on the rock on the upstream side of the slot in this region. This sensor showed that water pressure increased in a similar manner as shown in Figure 6 before the sensor failed.

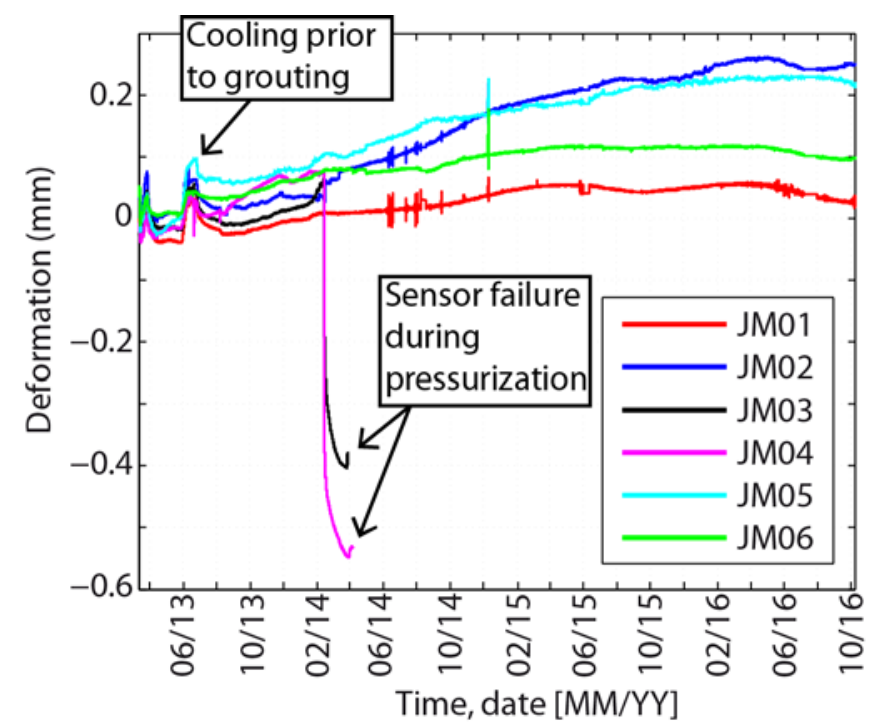

Figure 18 - Installed strain gauges.

Thereby, the concrete has most likely released on the upstream side of the slot in this region during the increasing water pressure, as illustrated in Figure 19 a). In addition, a small leakage 
between concrete and rock was observed near the top of the concrete as seen in Figure $19 \mathrm{~b}$ ). It should be noted that this is the same location where leakage of grout occurred during grouting. It is therefore likely that this location had not been sufficiently grouted which caused this leakage path. All leakage from the plug was gathered in a weir installed downstream of the concrete dome, see Figure 2. To prevent loss of water due to evaporation, a plastic sheet had been installed that enclosed the area upstream of the weir. From this weir, the leakage water was collected and measured automatically. The total leakage through the plug and the adjacent rock that was collected in the weir was $108 \mathrm{ml} / \mathrm{min}$ at this point and after this, the leakage at the top successively decreased and was $43 \mathrm{ml} / \mathrm{min}$ after 6 months, according to [1].

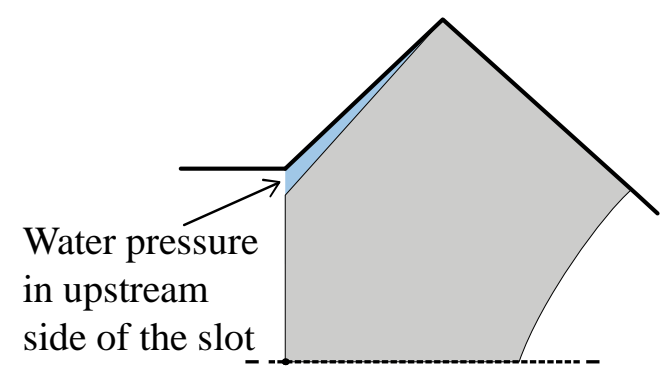

a)

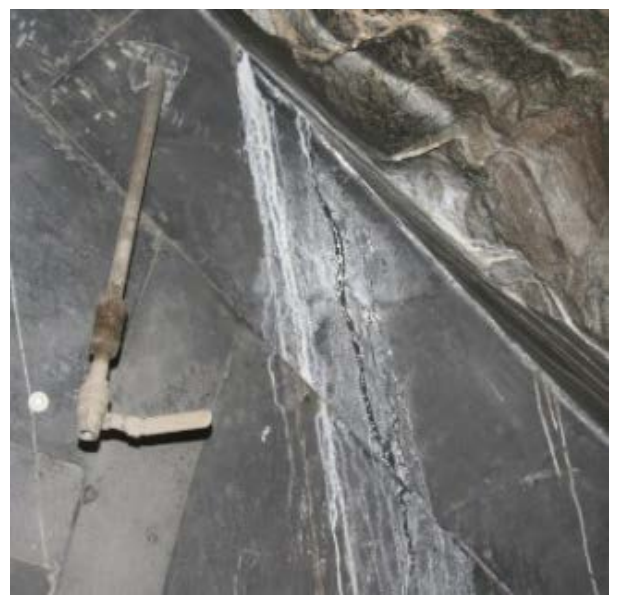

b)

Figure 19 - a) Illustration of water pressure in upstream side of the slot, b) photo of small leakage near the top of the concrete dome.

\section{5.}

\section{CONCLUSIONS}

In this paper, a full-scale test of the Dome plug intended to be used in the future repository for spent nuclear fuel in Sweden has been presented. The purpose of the full-scale test was to verify that it was possible to build the plug according to the design specifications. In addition, the purpose was also to evaluate that the design acted as expected during hardening and the serviceability state when it was subjected to hydrostatic pressure and estimate the water tightness of the structure.

The full-scale test showed that it was possible to build a plug according to the specifications and the whole installation worked as planned. The test showed that it was possible to build a concrete dome that could both carry its serviceability loads and be sufficiently water tight to allow for the bentonite seal to homogenize.

Due to the high autogenous shrinkage, the design was made for the unreinforced concrete to release from the rock during the hardening process by means of cooling. The measurements showed however that this was difficult to accomplish.

Based on the results from the strain gauges it can be observed that the contact grouting resulted in a thermal pre-stressing of the concrete dome plug. The obtained pre-stress varied between 0.5 
$\mathrm{MPa}$ and 3.5 MPa in the concrete dome, depending on the direction and location of the sensors. Only one sensor obtained the actual theoretical level of pre-stress and a few other sensors showed pre-stress above $70 \%$ of the theoretical value. The average pre-stress obtained from all strain gauges in operation was 53\%. If the concrete dome had released from the rock during the cooling stages, it is expected that all sensors would obtain their theoretical value. This indicates that the concrete dome only partially released from the rock in the top of the dome.

According to the measurements it is likely that the dome released partially, especially on the upstream side. At the location of the joint meters on the downstream side of the slot, the dome seems to have been constrained to the rock during the whole test. There could be several reasons for this. Naturally, the bond strength may have been higher than the previous test values that were used in design. However, if this was the case then numerical analyses showed that there would be a significant risk of cracking in the dome if it was subjected to the design values of the shrinkage without releasing from the rock. The full-scale test did however not show any visible cracks or leakages through the concrete (except for a small area in the interface between concrete and rock in the top of the dome as shown in Figure $19 \mathrm{~b}$ ). Other reasons for the discrepancy could of course be that numerical analyses were conservative or that the autogenous shrinkage of the concrete was less than assumed in the design.

\section{6.}

\section{FURTHER RESEARCH}

Considering that this is an extensive project, it has not been possible to present all results from the full-scale test. In this paper, the focus was on the early age behaviour and, especially, to evaluate if the concrete released from the rock as expected prior to grouting. The project is currently on-going and has moved in to the second phase. At the end of the serviceability load test (sustained load of $4 \mathrm{MPa}$ load for 3 years), a strength integrity test will be performed where the water pressure will be increased up to $9 \mathrm{MPa}$. After this, the whole plug will be demolished where a lot of test samples will be taken out. Before demolition, non-destructive testing will be performed to find if any internal damages are visible which could indicate interesting locations for core samples, etc. During the demolition, the thickness of the grout will be studied which will show the efficiency of the grouting and the results can be used to verify the results from the monitoring. Thereby, the results from the evaluations in this paper will be possible to verify with actual observations and measurements of the bond between concrete and rock and thickness of the grout in the future.

SKB will also continue to develop the concept for sealing deposition tunnels. The findings presented in this paper showed areas for improvement and further work. For instance, one important aspect is to study if the cooling scheme could be simplified and determine if the second cooling stage (stage B) is necessary. Another important aspect for further work is to continue develop the formwork used for the dome plug. As the test showed, the pressure on the formwork was much lower than the hydrostatic pressure due to the low casting rate.

\section{7.}

\section{ACKNOWLEDGEMENT}

The work presented in this paper regarding the full-scale test of the Dome plug that has been carried out in cooperation between SKB and Posiva Oy. The main project team consisted of the following people: 
SKB

Posiva Oy:

NCC:

Clay Technology:

KTH:

SWECO:

Palmer Engineering:

Vattenfall Teknik:

Uppländska berg:
Pär Grahm (Project leader), Patrik Hagman, Karin Nilsson, Anna Blomqvist, Behnaz Aghili, Pär Viberg, Mats Lundquist, Gunnar Ramqvist, Stefan Grandin Svärdh, Mikael Hedin

Petri Koho (Project partner), Petri Korkeakoski, Sanna Mustonen.

Hans Wimelius, Jonas Magnusson, Alexandre Mathern, Lars-Olof Dahlström, Christina Claeson-Jonsson.

Lennart Börgesson, Torbjörn Sandén, Mattias Åkesson, Linus Andersson, Viktor Jensen.

Richard Malm, Stefan Trillkott, Claes Kullberg.

Richard Malm, Daniel Eriksson.

Sten Palmer (Technical supervisor).

Tobias Gasch.

Rickard Karlzén

\section{REFERENCES}

1. Grahm P, Malm R, Eriksson D: "System design and full-scale testing of the Dome Plug for KBS-3V deposition tunnels - Main report,” Technical Report TR-14-23, Swedish Nuclear Fuel and Waste Management Co, Stockholm, Sweden, 2015, 206 pp.

2. Vogt C, Lagerblad B, Wallin K, Baldy F, Jonasson J-E: "Low $\mathrm{pH}$ self-compacting concrete for deposition tunnel plugs," Report R-09-07, Swedish Nuclear Fuel and Waste Management Co, Stockholm, Sweden, 2009, 78 pp

3. Malm R: “Low-pH concrete plug for sealing the KBS-3V deposition tunnels," Report R11-04, Swedish Nuclear Fuel and Waste Management Co, 2012,149 pp.

4. Malm R: "Instrumentation and evaluation of the concrete dome plug DOMPLU," TRITABKN Report 147, Department of Civil and Architectural Engineering, KTH Royal Institute of Technology, Stockholm, Sweden, 2014, 106 pp.

5. Emborg M: “Thermal stresses in concrete structures at early ages," $P h D$ thesis, report 1989:73 D, Department of Civil, Environmental and Natural Resources Engineering, Luleå University of Technology, Luleå, Sweden, 1989, 280 pp.

6. Kristiansson A: "Evaluation of a concrete plug: From the Dome Plug Experiment DOMPLU at Äspö HRL," MSc thesis, TRITA-BKN-Master Thesis 418, Department of Civil and Architectural Engineering, KTH Royal Institute of Technology, Stockholm, Sweden, 2014, 121 pp. 